\title{
A primary care physician's approach to a child with meningitis
}

\author{
I Govendera* (iD) , C Steyn ${ }^{\mathrm{a}}$ (D) , G Maricowitz ${ }^{\mathrm{b}}$, CC Clark ${ }^{\mathrm{i}}$ (D) and MC Tjale ${ }^{\mathrm{b}}$ \\ ${ }^{a}$ Department of Family Medicine, Sefako Makgatho Health Sciences University, Pretoria, South Africa \\ ${ }^{b}$ Department of Family Medicine, University of Limpopo, Polokwane, South Africa \\ *Corresponding author, email: indiran.govender@gmail.com
}

Background: Paediatric meningitis remains a common cause of childhood morbidity and mortality in developing countries. In children the peak age for meningitis is six to 12 months old, with $90 \%$ of cases occurring in children younger than five years. It is imperative that a primary healthcare physician be aware of and is capable of managing this life-threatening condition as most caregivers first present to a primary healthcare physician with their sick child.

Discussion: Common symptoms are headaches, photophobia, drowsiness, fatigue, unexplained crying, convulsions, irritability, and lethargy. Signs include fever, vomiting, neck stiffness and signs of increased intracranial pressure. Acute bacterial meningitis, especially meningococcal meningitis can present with petechiae and/or purpura. Cranial nerve palsy occurs commonly in cryptococcal meningitis, which can occur as part of immune reconstitution inflammatory syndrome (IRIS) after initiation of antiretroviral therapy. Older children may present with behavioural changes and localising signs such as hemiparesis and coma. Conclusion: This paper discusses the lumbar puncture technique and findings, drug and non-drug management, information on chemoprophylaxis for bacterial meningitis, and the possible complications of meningitis in children. This is an important area for the primary care physician as they are usually the first port of call by caregivers.

\section{Introduction}

Meningitis is commonly defined as inflammation of the meninges surrounding the brain and spinal cord. In children, the peak age for meningitis is six to 12 months old, with $90 \%$ of cases occurring in children younger than five years.

\section{Meningitis can be caused by: ${ }^{2}$}

- Viruses: e.g. herpes simplex, cytomegalovirus, enterovirus and varicella zoster

- Bacteria: e.g. Neisseria meningitides, Streptococcus pneumoniae, Haemophilus influenzae and Escherichia coli

- Fungi: e.g. cryptococcal meningitis

- Tuberculosis (TB)

Paediatric meningitis remains a common cause of childhood morbidity and mortality in developing countries. Knowledge of the organisms that cause meningitis can assist us in developing empirical antibiotic regimes, as well as recommending the necessary immunisations for primary health care.

Table 1 shows the causative organisms that were found in a retrospective review of 557 meningitis cases at a referral centre in Cape Town, South Africa between 2007 and 2009.

It is imperative that a primary healthcare physician be aware of and can manage this life-threatening condition, as most care givers first approach a primary care physician with their sick child.

\section{Signs and symptoms}

Symptoms include headache and photophobia. ${ }^{3}$ Cryptococcal meningitis can present with acute or chronic headache in the older HIV-infected child. TB meningitis can have a gradual onset with vague complaints of drowsiness, fatigue, and headache. In new-born infants, symptoms such as poor suckling, vomiting, recurrent apnoea, temperature instability and seizures should raise suspicions. Infants (children below 1 year) frequently present with fever, irritability, vomiting, seizures, hypothermia, lethargy, respiratory distress, jaundice, poor feeding, diarrhoea, restlessness, excessive crying and/or a bulging fontanelle., Infants often do not present with meningism, thus it is imperative to always have a high index of suspicion with any of the mentioned signs. Toddlers or children present with the triad of headache, fever and vomiting. ${ }^{4}$ Meningitis should furthermore be suspected with unexplained crying. ${ }^{6}$

An important sign in meningitis is neck stiffness - the neck is stiff on flexing as it is painful for the child. If the child is young or uncooperative when you test for neck stiffness or meningeal irritation, place the child so that the head and shoulders are over the edge of the bed. If neck stiffness is still present, the test is positive. Consider other causes of neck rigidity. This sign can be absent in young infants. ${ }^{6}$

In younger infants, signs of increased intracranial pressure (ICP), such as a bulging anterior fontanelle, can also be a sign indicating meningitis. Acute bacterial meningitis, especially meningococcal meningitis, can present with petechiae and/or purpura and hypothermia in neonates. Cranial nerve palsy is frequently a sign in cryptococcal meningitis. ${ }^{3}$

Papilloedema is not a useful sign in young children with meningitis as it is difficult to elicit and may be absent with acutely raised ICP. Papilloedema may take hours to weeks to develop in children with raised ICP. Cryptococcal meningitis can occur as part of immune reconstitution inflammatory syndrome (IRIS) after initiation of antiretroviral therapy. ${ }^{3}$ TB meningitis can have a gradual onset with vague complaints such as vomiting, fever, weight loss and irritability. Later signs including convulsions and neurological fall-out may also occur. Furthermore, older children could present with behavioural changes. Examination may reveal the signs mentioned above, as well as localising signs such as hemiparesis, coma and choroidal tubercles. ${ }^{3}$

\section{Investigations}

Table 2 lists the investigations undertaken. 
Table 1: Classification of meningitis at a referral centre in Cape Town, South Africa. Adapted from Wolzak et al. ${ }^{2}$

\begin{tabular}{|l|c|}
\hline Causative organism & Percentage of total \\
\hline M. tuberculosis & $22 \%$ \\
\hline S. pneumonia & $4 \%$ \\
\hline K. pneumoniae & $3 \%$ \\
\hline H. influenzae & $<1 \%$ \\
\hline Viral & Most common, aseptic CSF test results \\
\hline
\end{tabular}

Table 2: Investigations ${ }^{3}$

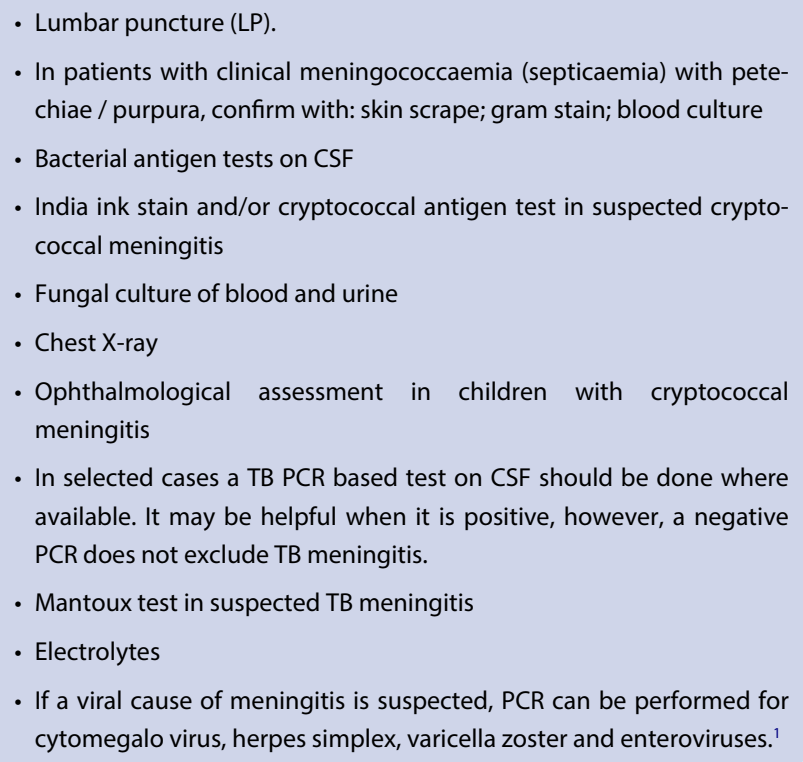

\section{Lumbar puncture (LP)}

The contra-indications to LP include infection at the site where the LP is to be performed, congenital anomalies of the lower spine (e.g. meningomyelocoele), bleeding diathesis (e.g. disseminated intravascular coagulation (DIC) and haemophilia) and signs of raised ICP. Furthermore, an LP should not be performed on an extremely ill infant or child as this might exacerbate the condition.?

Should the patient present with the clinical signs of severely raised ICP (i.e. impending cerebral herniation; decreased or sudden deterioration of level of consciousness; decerebrate or decorticate posturing; neurogenic hyperventilation; unequally dilated or poorly reactive pupils), do not do an LP but initiate treatment immediately. An LP done with meningeal signs due to raised ICP would prove fatal, because tonsillar herniation would follow the LP.

If a depressed level of consciousness or focal neurological signs are present, it is useful to do a computed tomography (CT) scan before doing an LP. ${ }^{7}$ It is however critical not to rely on imaging only to determine the presence of raised ICP. This is important because CT scans, which are used more often in primary care than magnetic resonance imaging (MRI), detects raised ICP only in about $25 \%$ of cases, although CT imaging is useful to determine the causes of raised ICP. A thorough clinical evaluation of the patient is therefore important. Raised ICP may result in Cushing's triad of increased systolic pressure (including widened pulse pressure), bradycardia and irregular breathing. ${ }^{8}$ Blood pressure and pulse rate measurement should therefore be part of the clinical examination.

A single dose of mannitol could also be given to determine if the ICP is raised. Mannitol lowers the ICP one to five minutes after intravenous administration, and its peak effect is at $40 \mathrm{~min}$. A single dose might therefore result in a transient improvement of signs and symptoms of raised ICP. It is however important to limit the mannitol to only one dose, as the blood brain barrier becomes permeable to mannitol and it may worsen vasogenic oedema. ${ }^{8}$ The dose of mannitol in children between one month and 12 years old is $0.25-1.5 \mathrm{~g} / \mathrm{kg}^{9}{ }^{9}$

LP is also contraindicated and must be deferred in the older child who presents with behaviour changes, changes in mood or personality. These changes must be taken seriously and may imply that the ICP is raised, or that cerebral oedema may be present., ${ }^{3,7}$

As an LP is an important part of the complete work-up of the child with suspected meningitis, it is imperative that the correct procedure is followed if the LP is done. Be ready to resuscitate the child if necessary and ensure that the drugs and equipment necessary for resuscitation are at hand.

Collect a blood glucose sample before doing the LP for comparison with blood CSF glucose. ${ }^{7}$ CSF glucose is generally about two thirds of the serum glucose. CNS infections can cause lowered CSF glucose levels, although glucose levels are usually normal in viral infections. Bacterial and TB meningitis should be suspected if the CSF glucose is less than $2.5 \mathrm{mmol} / \mathrm{l}^{10}$

Proper positioning and restraint of the child is essential for the LP to be successful. Position the child so that he/she is facing the assistant and ensure that he/she is more towards the side of the table or couch from which you will work. The preferred position

Table 3: CSF finding of meningitis ${ }^{1,3,4}$

\begin{tabular}{|l|c|c|}
\hline Component & Normal child & Normal newborn \\
\hline Appearance & Crystal clear & Crystal clear \\
\hline WBC $(/ \mu \mathrm{l})$ & $0-6$ & $0-30$ \\
\hline Neutrophils $\left(\times 10^{6} / \mathrm{l}\right)$ & 0 & $2-3$ \\
\hline Lymphocytes $\left(\times 10^{6} / \mathrm{l}\right)$ & 0 & 0 \\
\hline Glucose $(\mathrm{mmol} / \mathrm{l})$ & $2.2-4.4 \frac{1}{2}-2 / 3$ of blood & $1.8-6.71 / 2-2 / 3$ of blood \\
glucose & $0.2-1.5$ \\
\hline Protein $(\mathrm{mg} / \mathrm{dl})$ & $0.2-0.4$ & $0-2$ \\
\hline RBC $(/ \mu \mathrm{l})$ & $0-2$ & \\
\hline ADA $(\mathrm{IU} / \mathrm{l})$ & & 0.5 \\
\hline
\end{tabular}

Bacterial meningitis
Turbid/purulent
$>1000(\uparrow \uparrow)$
$>50 \%(\uparrow \uparrow)$ Predominant
$\uparrow$
$<1.66(\downarrow \downarrow)<1 / 2$ blood
glucose
$>1.0(\uparrow)$
$0-10$

Viral meningitis
Clear/turbid
$100-500(\uparrow)$
$<40 \%(\uparrow)$
$\uparrow$
Low normal $>1 / 2$ blood
glucose
$0.2-2.0(\uparrow)$
$0-2$

TB meningitis

Turbid/viscous

$\mathrm{WBC}=$ white blood cells, $\mathrm{RBC}=$ red blood cells, $\mathrm{ADA}=$ adenosine deaminase 
Table 4: Antibiotics in bacterial meningitis

Neonates and children under 3 months of age:
- Ceftriaxone $100 \mathrm{mg} / \mathrm{kg}$ daily, or Cefotaxime $50 \mathrm{mg} / \mathrm{kg} 6$ hourly
- Add Ampicillin $50 \mathrm{mg} / \mathrm{kg} 12$ hourly
Infants over 3 months of age and children:
- Ceftriaxone or cefotaxime as above
- Ampicillin \pm vancomycin can be added depending on sensitivity
testing
Usual duration of treatment if the child has had a minimum of 5 fever free
days:
- N. meningitides: 7 days
- S. pneumoniae: 10 days
- H. influenza: 10 days
- Gram negative sepsis: 21 days

Table 5: Treatment of cryptococcal meningitis: ${ }^{3}$

Initial treatment:
- Amphotericin B $0.7-1.0 \mathrm{mg} / \mathrm{kg} /$ day IVI as a daily infusion over $4 \mathrm{~h}$
PLUS
- Fluconazole $12 \mathrm{mg} / \mathrm{kg} /$ day IVI for two weeks; maximum dose $800 \mathrm{mg}$
- Pre-hydration before amphotericin B administration to prevent renal
impairment:
- Normal saline $0.9 \% 20 \mathrm{ml} / \mathrm{kg}$ IVI PLUS Potassium chloride $20 \mathrm{mmol} / \mathrm{I}$
infused over $2-4 \mathrm{~h}$
Consolidation treatment for 2 weeks:
- Fluconazole $12 \mathrm{mg} / \mathrm{kg} /$ day orally; maximum dose $800 \mathrm{mg}$
Maintenance treatment:
- Fluconazole $6 \mathrm{mg} / \mathrm{kg} /$ day orally; maximum dose $400 \mathrm{mg}$
Discontinue maintenance treatment:
- Children < 6 years on ART: CD4 count $>25 \%$ for at least 6 months.
- Children > 6 years on ART: CD4 count $>200$ for at least 6 months.
- Adolescents on ART: CD4 count increases to between $100-200$ cells/
mm 3 for at least $6 \mathrm{months.} \mathrm{Restart} \mathrm{prophylaxis} \mathrm{if} \mathrm{CD4} \mathrm{count} \mathrm{drops} \mathrm{be-}$
low the thresholds above

is for the child to be seated, with legs straightened and back curved forward. Alternatively, the child can lie on his side with the back at a right angle to the bed, and held firmly in a flexed position. Maintain the neck in partial extension and not flexed toward the chest (refer to Figure 1).

Ensurethat a sterile procedure is followed and maintained throughout. The LP should be done between the fourth and fifth lumbar processes, using a $22-24$ gauge bevelled needle. Angle the needle towards the child's umbilicus and gradually advance for $1 \mathrm{~cm}$ until a slight 'pop' is felt when the needle enters the subarachnoid space (refer to Figure 2). Collect the CSF into each of three test tubes ensuring that each tube contains $0.5-1 \mathrm{ml}$ of fluid. Use a fluoride tube for testing CSF glucose and two plain tubes for biochemistry and microbiology. (Note: The National Health Laboratory Service use colour-coded tubes: grey for glucose, and plain tubes with a red stopper for other tests (light brown when red-stoppered tubes are not available, e.g. in Limpopo).

Once the CSF is collected, the needle can be removed, and direct pressure should be applied to the puncture site with a sterile cotton wool swab until bleeding or leakage of fluid stops. Subsequently, a sterile dressing and adhesive bandage should be applied to the site.

\section{CSF findings}

Any abnormal findings on a lumbar puncture should be taken seriously. Table 3 lists the characteristic CSF features for each type of meningitis.

If the CSF protein is significantly elevated, then consider either TB meningitis or obstruction (either due to hydrocephalus or obstruction at the spinal cord level). ${ }^{10}$

If the CSF has a polymorphonucleosis, but the bacterial antigens are negative, the following could be considered.

In viral meningitis/encephalitis polymorphs may predominate early illness. Polymorph predominance is also seen in TB meningitis. Partially treated bacterial meningitis may present in the same manner. ${ }^{11}$ In these instances, it is vital to contact the referring facilities to confirm the prior use of antibiotics.

In these children neighbourhood syndrome should also be considered. Examine them for mastoiditis, sinusitis, otitis media, and rule out brain abscess. ${ }^{12}$

\section{Electroencephalogram (EEG)}

Seizures are often non-convulsive in critically ill patients with suspected meningitis, patients who are not fully conscious, or patients who take longer than expected to regain consciousness. In these patients, EEG may indicate the presence of a subclinical status epilepticus. ${ }^{13}$

If periodic lateralised epileptiform discharges are seen on EEG, it is indicative of herpes encephalitis. In children with these EEG changes, acyclovir should be added to the management. ${ }^{14}$

In meningitis, the EEG shows various degrees of slow-wave abnormalities, depending on the type of meningitis and the degree of involvement of the brain. ${ }^{15}$

In acute purulent meningitis, moderate to severe diffuse slowwave abnormalities are often present, and patients with seizures show paroxysmal epileptiform activity. EEG findings in tuberculous meningitis vary according to the location of the inflammatory process, e.g. in basal meningitis the EEG may be normal and show only mild nonspecific slowing. In children, as with purulent meningitis, more severe slow-wave abnormalities are present. The EEG may be normal or show only mild slowing in aseptic meningitis. The findings are not necessarily indicative of the clinical severity of the disease or the development or degree of post-infectious complications. ${ }^{15}$

The EEG usually returns to normal in patients with uncomplicated meningitis. Persistent EEG abnormalities or evidence of deterioration in the EEG may, however, suggest an unfavourable course, the development of a complication such as an abscess or hydrocephalus, or the presence of residual brain damage. ${ }^{15}$

\section{Management of meningitis}

Once the diagnosis of meningitis has been made, the management should include general and supportive measures for all children (refer to Table 4). ${ }^{3}$ All children with confirmed or suspected meningitis must be referred to a higher level of care after receiving a single dose of ceftriaxone $80 \mathrm{mg} / \mathrm{kg}$ intra muscular injection (IMI). ${ }^{16}$ Ideally, they should be admitted to a high or intensive care unit if possible and appropriate (especially children with acute bacterial meningitis). Adequate nutrition is imperative. Rehabilitation with physiotherapy and occupational therapy is 
Table 6: Treatment of TB meningitis

Treatment is a 6-month regimen of all 4 of the following drugs:
- Rifampicin $20 \mathrm{mg} / \mathrm{kg}$ orally as a single daily dose
- Isoniazid $20 \mathrm{mg} / \mathrm{kg}$ orally as a single daily dose
- Pyrazinamide $40 \mathrm{mg} / \mathrm{kg}$ orally as a single daily dose; maximum dose
$2000 \mathrm{mg}$
- Ethionamide $20 \mathrm{mg} / \mathrm{kg}$ orally as a single daily dose; maximum dose
$1000 \mathrm{mg}$

Table 7: Complications of meningitis:

Complications during acute infection:
- Cerebral oedema (deteriorating level of consciousness)
- Shock
- Metastatic infection, e.g. arthritis, pneumonia, pericarditis
- Disseminated intravascular thrombosis
- Syndrome of inappropriate antidiuretic hormone secretion (SIADH)
- Seizures and symptomatic epilepsy
- Subdural effusions and empyema
- Brain abscess
- Hyponatraemia
Post recovery complications:
- Hydrocephalus
- Intellectual disability
- Blindness and sensorineural deafness
- Behavioural problems
- Motor paralysis e.g. hemiparesis

indicated for most patients after acute illness and, furthermore, audiometry follow-up after acute illness is essential. ${ }^{4}$

Pharmacological management includes analgesia with paracetamol for all children with meningitis (oral dose $15 \mathrm{mg} / \mathrm{kg}$ / dose, 6 hourly). ${ }^{3}$ In viral meningitis the treatment is supportive. There is often a dramatic relief of headache after the LP. If the diagnosis is doubtful, treat for bacterial and tuberculous meningitis. ${ }^{4}$ With bacterial meningitis, start antibiotic treatment immediately after drawing blood for culture, as prognosis is directly related to the length of time between onset of symptoms and treatment (refer to Table 5). ${ }^{3}$

Previously, corticosteroids were recommended in patients with acute bacterial meningitis (dexamethasone $0.15 \mathrm{mg} / \mathrm{kg}$ IV 6 hourly for three days; start with the antibiotic therapy if $H$. influenza was cultured). ${ }^{1,3,4}$ However, a recent meta-analysis showed that adjunctive dexamethasone does not significantly reduce death or neurological disability. ${ }^{17}$ The use of adjunctive corticosteroids, therefore, remains controversial and recent guidelines do not recommend it.

It is important that head circumference is measured daily in children with bacterial meningitis, i.e. serial head circumference measurements. This will aid in the early detection of complications like hydrocephalus, increased intracranial pressure and brain abscess, and ensure timely referral for neurosurgical intervention. ${ }^{18}$

TB meningitis is difficult to differentiate from acute bacterial meningitis. If in doubt, treat for both conditions (refer to Table 6). ${ }^{3}$

Consider prolonging treatment for another three months if there are concerns about ongoing disease and consult with a specialist. In the case of suspected/confirmed multi-drug resistant TB (MDRTB), refer the patient for specialist treatment immediately. Steroid therapy is recommended (prednisone $2 \mathrm{mg} / \mathrm{kg}$ as a single oral daily dose for 4 weeks; maximum dose $60 \mathrm{mg}$ ), and should be tapered to stop over a further two weeks. ${ }^{3}$

Adequate fluid management in children with meningitis is important to maintain cerebral perfusion. These patients are at high risk of developing the syndrome of inappropriate antidiuretic hormone $(A D H)$ secretion (SIADH) that presents with hyponatraemia. If SIADH develops, the child can develop seizures even after antibiotic therapy initiation. This syndrome occurs because the body attempts to increase cerebral perfusion pressure. ${ }^{11}$

The best way to prevent hyponatraemia in meningitis is to ensure normovolaemia and to avoid excessive administration of free fluid. The patient's hydration status and all electrolytes should be

Table 8: Chemoprophylaxis

N. meningitides:

H. influenza:
Ciprofloxacin, oral, as a single dose

- If $<6$ years of age: $10 \mathrm{mg} / \mathrm{kg}$

- If 6 - 12 years if age: $250 \mathrm{mg}^{16}$

- If $>12$ years of age: $500 \mathrm{mg}$

OR

Ceftriaxone, intramuscular (IM), as a single dose

- If $<12$ years of age: $125 \mathrm{mg}$

- If $>12$ years of age: $250 \mathrm{mg}$

Close contacts who are pregnant:

- Ceftriaxone $250 \mathrm{mg}$ IM

For all contacts under 5 years who are household contacts (including index case) or day care contacts:

- Rifampicin, oral, $20 \mathrm{mg} / \mathrm{kg} /$ dose, once daily for 4 days

- Maximum dose: $600 \mathrm{mg}$

- Neonatal dose: $10 \mathrm{mg} / \mathrm{kg} /$ dose, once daily for 4 days

- Hib vaccination:

- Update Hib vaccination in unimmunised or partially immunised children.

- Give Hib booster to all children < 5 years including index case.

- Hib vaccination on its own is not protective in contact situation. 


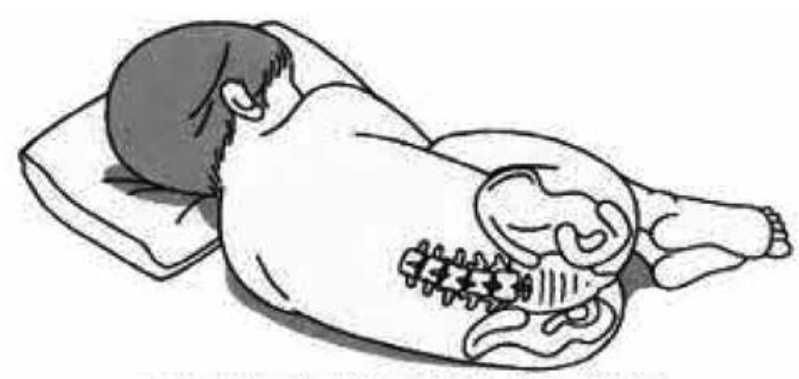

Lumber Puncture position

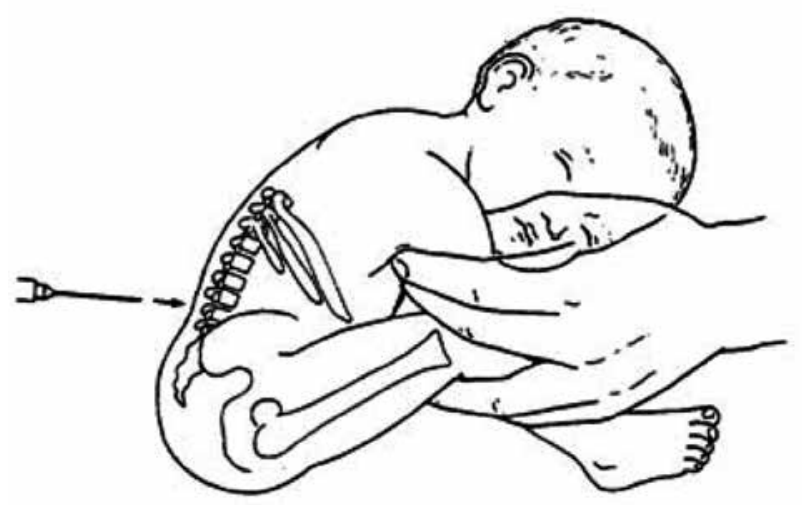

Having the Lumbar Puncture (LP)

Figure 1: Lumbar puncture positions for a child.
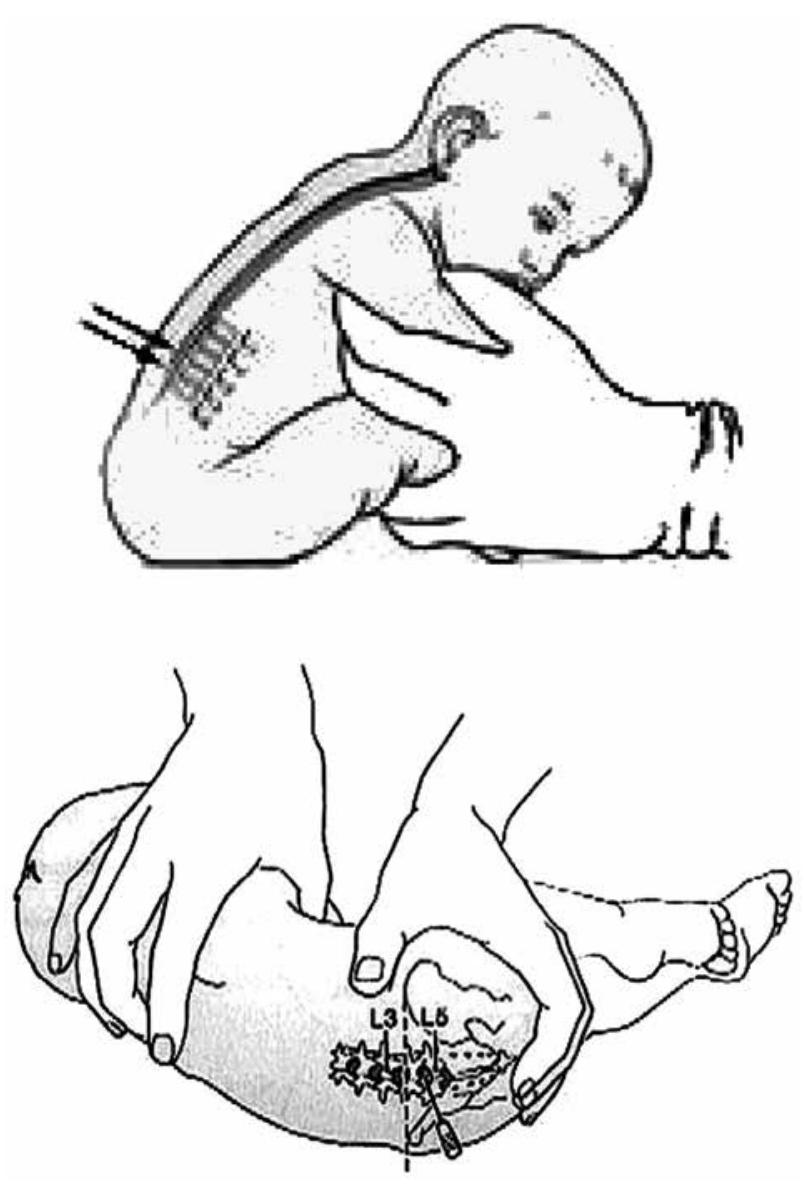

Figure 2: Needle positions for lumbar puncture. monitored and corrected on a regular basis. Children with severe hyponatraemia must be admitted for intensive care. ${ }^{11}$

Should a child still have temperature spikes after two weeks of antibiotic treatment, imaging should be done to determine whether the child has developed a brain abscess, empyema, subdural effusion or hydrocephalus, in which case they should be referred to a neurosurgeon for possible neurosurgical intervention. If these children are immune compromised, they could also have TB or cryptococcal meningitis instead of bacterial meningitis, and the treatment should be adjusted accordingly. It is important to rule out possible resistance to antimicrobials, endocarditis with an echocardiogram, and septic arthritis and osteomyelitis as other foci of infection. ${ }^{3,4,6}$ These children must be managed in specialised care centres.

\section{Complications of meningitis}

Meningitis may result in serious complications especially if diagnosis and/or treatment is delayed (refer to Table 7).1,3,4 Mortality in neonates is $15-20 \%$, and in children $4-8 \%$. The highest mortality is seen in patients with acute bacterial meningitis.

Meningitis is one of the leading causes of acquired deafness and approximately $8 \%$ of survivors will experience some degree of permanent hearing loss. ${ }^{19}$ Preferably, all children should have a hearing test within four weeks of being well enough to test after bacterial meningitis. ${ }^{20}$

Recently, a more favourable disease prognosis has been documented due to improvements in medical care, and neurobehavioral sequelae, such as impairments in cognitive function and academic achievement, have been identified in many meningitis survivors. Subtle deficits in visual-motor coordination, auditory perception, and language functions are reported. Generally, meningitis survivors performed more poorly than peers with respect to intellectual functions, particularly verbal ability, motor skills, and educational progress, as some presented with attention deficit hyperactive disorder (ADHD). ${ }^{21}$ It is, therefore, important that children be followed up post meningitis to ensure optimal academic performance and development.

\section{Chemoprophylaxis for close contacts of bacterial meningitis ${ }^{3}$}

A close contact is defined as someone living in the same household, dormitory or institution, or children attending the same crèche, or any other 'kissing' contact. Healthcare workers who have intimate contact should receive prophylaxis (refer to Table 8).

In the revised expanded programme on immunisation (EPI) of 2016, ${ }^{22}$ all children in South Africa receive immunisations against the common bacterial meningitis, namely hexavalent immunisations (protection against diphtheria, pertussis, tetanus, polio, $H$. influenzae type $B$ and hepatitis $B$ given at six weeks, 10 weeks, 14 weeks and 18 months) and PCV13 (pneumococcal conjugate vaccine given at six weeks, 14 weeks and 9 months). ${ }^{3}$

\section{Precautions for travellers to a meningococcal endemic region}

$N$. meningitides infection occurs worldwide, but the highest incidence is in the 'meningitis belt' of sub-Saharan Africa (refer to Figure 3). Meningococcal disease is hyperendemic in this region 


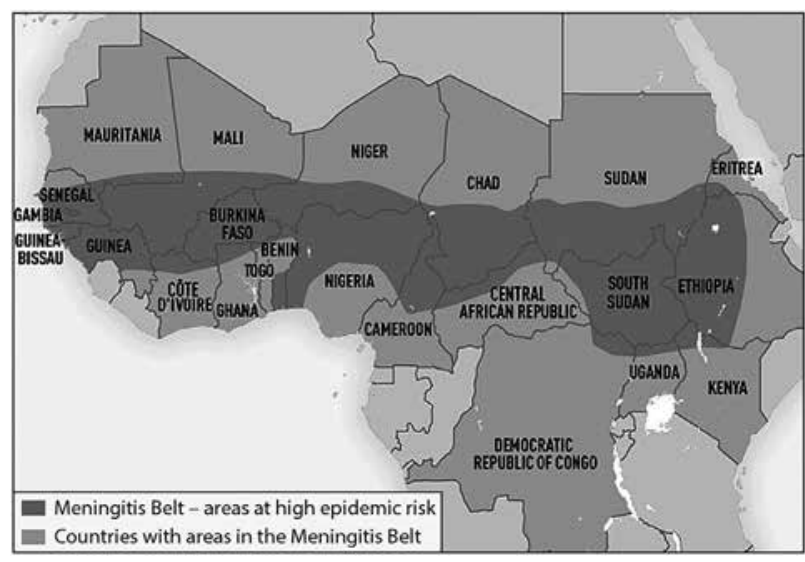

Figure 3: The meningitis belt. Adapted from MacNeil \& Meyer, 2015.23

and periodic epidemics during the dry season (December-June) reach up to 1000 cases per 100000 population.

Outside the meningitis belt, infants have the highest rates of disease, while high rates are seen up to 30 years of age in meningitis belt countries. Risk for travellers is highest in those visiting meningitis belt countries who have prolonged contact with local populations during an epidemic. The Hajj has been associated with outbreaks of meningococcal disease during the pilgrimage in returning pilgrims and their contacts.

Travellers who visit or reside in countries where meningococcal disease is hyper endemic or epidemic, including the meningitis belt of sub-Saharan Africa during the dry season (DecemberJune), should receive a quadrivalent meningococcal vaccination, including children from two months of age. ${ }^{23}$

Visitors to Saudi Arabia arriving for the purpose of Hajj/Umrah or for seasonal work are required to submit a certificate of vaccination with the quadrivalent (ACYW135) vaccine against meningitis, proving the vaccine was administered no less than 10 days before arrival. The conjugate vaccine is the valid option, when available, and confers a protection of at least five years. The vaccine should have been administered not more than five years prior to entry into the country. The conjugate vaccine is licensed for persons between nine months and 55 years old. The responsible authorities in the visitor's country of origin should ensure that adults and children aged two years and above are given at least one dose of the quadrivalent vaccine and state the name of the vaccine used clearly on the vaccination card. ${ }^{24}$

The conjugate meningococcal vaccine certificate is valid for five years. However, the certificate must clearly state that the Hajji received the conjugate meningococcal vaccine. If the vaccine type is not indicated in the certificate, then it will be assumed that it is not the conjugate vaccine and the validity of the certificate will to be for three years. ${ }^{24}$

The above requirements apply to visitors to Saudi Arabia from countries in the African meningitis belt. In addition, chemoprophylaxis will be administered at port of entry to lower the rate of carriers. ${ }^{24}$

\section{Conclusions}

Meningitis is a condition that is not only life threatening, but can also have serious long-term complications in children. As caregivers often present to primary healthcare facilities with their children, it is imperative that the primary healthcare practitioners be able to recognise and treat meningitis correctly and appropriately in order to save lives. Children with disabilities subsequent to a bout of meningitis should receive adequate rehabilitation to improve their quality of life.

Disclosure statement - No potential conflict of interest was reported by the authors.

\section{ORCID}

I Govender (i) http://orcid.org/0000-0003-0126-8087

C Steyn (iD http://orcid.org/0000-0001-6062-8981

CC Clark (D) http://orcid.org/0000-0001-9129-1007

\section{References}

1. Essential Med Notes. Toronto Notes for Medical Students, Inc. 31st ed.; 2015.

2. Wolzak NK, Cooke ML, Orth $\mathrm{H}$, et al. The changing profile of pediatric meningitis at a referral centre in Cape Town. J Trop Pediatr. 2012;58(6):491-5. https://doi.org/10.1093/tropej/fms031

3. Hospital level paediatrics, standard treatment guidelines and essential medicine list. Department of health, Republic of South Africa; 2013.

4. Motala C, Davidson A, Figaji A, et al. Handbook of paediatrics. 7th ed. Oxford university press; 2010.

5. Meningitis Souter J. Vaccines and prophylaxis. SA pharmaceutical journal. 2010 Sept:44-60.

6. De Villiers FPR. Practical management of paediatric emergencies. 5th ed. Oasis purple; 2008.

7. Mash B, Blitz J. 2015. South African family practice manual. 3rd ed. Van Schaik.

8. Roytowski D, Figaj A. Raised intracranial pressure: What it is and how to recognise it. CME. 2013;31(3):85-90.

9. Tavakkoli F. Review of the role of mannitol in the therapy of children. 18th Expert Committee on the selection and use of Essential Medicines. Mannitol review (Children); 2011(16).

10. Seehusen DA, Reeves MM, Fomin DA. Cerebrospinal fluid analysis. Am Fam Physician. 2003;68(6):1103-9.

11. Voss L, Nicholson R. Meningitis. Starship Children's Health Clinical Guideline (document on the Internet). Updated 2009. Available from: http://www.adhb.govt.nz/starshipclinicalguidelines/_Documents/ Meningitis.pdf

12. Province of KwaZulu-Natal Health Services. Paediatric Guidelines. Meningitis (document on the Internet). 2007. Available from: http:// www.kznhealth.gov.za/chrp/documents/Guidelines/Guidelines\%20 Paeds/CNS/Meningitis\%20CHRP\%202007.pdf

13. Mehta A, Nallasamy K. Neurocritical care monitoring. J Pediatr Crit Care. 2015;2(3):35-9. https://doi.org/10.21304/2015.0203.00077

14. Saini AG, Singhi P. CNS infections in childhood. J Pediatr Crit Care. 2015;2(3):40-8. https://doi.org/10.21304/2015.0203.00078

15. Metwally Y. EEG in meningitis. Online brainmapping (document on the internet). Updated 2009. Available from: http://www.profyasser. files.wordpress.com

16. Primary health care, standard treatment guidelines and essential medicine list. Department of health, Republic of South Arica; 2014.

17. Boyles TH, Bamford C, Bateman K, et al. Guidelines for the management of acute meningitis in children and adults in South Africa. South Afr J Epidemiol Infect. 2013;28(1):5-15.

18. The Royal Children's Hospital Melbourne. Clinical Practice Guidelines. Meningitis - encephalitis (document on the Internet). Updated 2016. Available from: http://www.rch.org.au/clinicalguide_index/ Meningitis_Guideline 
19. Edmond KA, Clark VS, Korczak C, et al. Global and regional risk of disabling sequelae from bacterial meningitis: a systematic review and meta-analysis. Lancet Infect Dis. 2010;10(5):317-28. https://doi.org/10.1016/S1473-3099(10)70048-7

20. NICE guideline. Bacterial meningitis and meningococcal septicaemia in children (document on the internet). Updated 2010. Available from http://www.nice.org.uk/nicemedia/live/13027/49437/49437.pdf

21. Anderson V, Anderson P, Grimwood K, et al. Cognitive and executive function 12 years after childhood bacterial meningitis: effects of acute neurologic complications and age of onset. J Pediatr Psychol. 2004;29(2):67-81. https://doi.org/10.1093/jpepsy/jsh011
22. Expanded programme on immunization. 2016. Department of Health, Republic of South Africa.

23. MacNeil JR, Meyer SA. Meningococcal disease. Infectious diseases related to travel. CDC traveller's health; 2015.

24. The Ministry of Health of Saudi Arabia. Health Requirements for Travellers to Saudi Arabia for Pilgrimage to Makkah (document on the Internet). Updated 2017. Available from: http://www.moh.gov.sa/ en/hajj/pages/healthregulations.aspx

Received: 07-12-2016 Accepted: 17-10-2017 